\title{
A 3D numerical mode for HST induced vibrations
}

\section{Pedro Galvín, José Domínguez}

Escuela Superior de Ingenieros, Universidad de Sevilla, Camino de los Descubrimientos s/n, 41092 Sevilla, Spain

pedrogalvin@us.es,jose@us.es

\begin{abstract}
A general numerical model for the analysis of soil motion due to high-speed train passage and effects on nearby surface and underground structures is presented in this paper. In contrast to other existing approaches, effects on a particular structure and the influence of non-uniform soil conditions along the track can be evaluated. Numerical results are obtained for different situations and some of them are compared with existing experimental records. The experimental values are to a large extent reproduced by the present numerical approach.
\end{abstract}

\section{Introduction}

Many new high-speed train (HST) lines are being constructed in Europe, Asia and the USA. The growing interest in the analysis of train-induced vibrations in recent years calls for additional studies to be conducted in this area. Problems such as train vibrations, soil free field vibrations produced by train traffic, and dynamic effects on structures situated near the track are much more important in the case of HSTs than for conventional ones. A thorough analysis of these effects is required in order to ensure security and comfort in the trains and to avoid eventual problems for nearby constructions which may be affected by vibrations induced by waves transmitted through the soil. Particularly serious would be situations in which the train speed may be higher than that of the surface waves in the underlying soil. Such a possibility was completely unthinkable for conventional trains but it is now something that should be taken into account when HSTs operate at locations with soft soils or underground discontinuities that may result in relatively low surface wave speed. Worthy of note here is the record speed of $574.8 \mathrm{~km} / \mathrm{h}$ set by an Alstom train travelling between Paris and Strasburg in April 2007.

The study of these problems requires employing comprehensive models that can take into account significant factors related to the characteristics of the train, the track, and the local soil properties. Nearby structures should also be modelled in case where the effects on these structures are being analysed. The final objective of this paper is to make gains in being able to accurately predict soil wave propagation due to the passage of HST and to forecast vibrations that will affect existing structures and those to be constructed.

\section{Numerical model}

The purpose of this section is to briefly outline the numerical model developed by the authors to predict vibrations induced by rail traffic. The model is based on the three-dimensional formulation of the BE method [1] coupled with the FEM [2]. Coupling of both meshes into a single model is carried out by means of an iterative algorithm [3]. More extensive treatment of the model can be found in Refs. [4-6]. Soil, ballast and structures are represented using time domain approach. Soil is represented by a BE model. Ballast and structures can be represented by $\mathrm{BE}$ or FE models.

The formulation presented is more general than other existing approaches. It permits full coupling between the soil and nearby structures; it is able to consider embankment, ballast and other local effects, as well as coupling with structures that brake uniformity of the geometry along the track direction.

\section{Half-space under constant speed point load}

Motion induced in a homogeneous elastic half-space by a point load travelling at constant speed is studied using the numerical model summarized in the previous section.

Figure 1 shows the vertical displacements over an area close to the load. Displacements are normalized as $\mathrm{G}(\tau)=\pi \mathrm{w}(\mathrm{t}) \mu \mathrm{B} / \mathrm{P}$, where $\mathrm{W}(\mathrm{t})$ represents normal displacements; $\mu$ the shear modulus; $2 \mathrm{~B}=25 \mathrm{~m}$ is the wide of the discretized surface and $\mathrm{P}$ the load value. Results are shown for four different load velocities corresponding to $0<\mathrm{v}<\mathrm{C}_{\mathrm{R}} ; \mathrm{C}_{\mathrm{R}}<\mathrm{v}<\mathrm{C}_{\mathrm{S}}$; 
$\mathrm{C}_{\mathrm{S}}<\mathrm{v}<\mathrm{C}_{\mathrm{P}}$ and $\mathrm{C}_{\mathrm{P}}<\mathrm{v}<\infty$, where $\mathrm{C}_{\mathrm{R}}$ is the Rayleigh wave velocity, $\mathrm{C}_{S}$ is the $\mathrm{S}$-wave velocity and $C_{P}$ is the $P$-wave velocity in the soil The symmetry of the soil motion is lost as $\mathrm{v}$ increases due to radiation effect of the Mach waves. The typical Mach cone is observed in the case when $v>C_{p}$. The vertical displacements have a maximum for load speed of about $\mathrm{C}_{\mathrm{R}}$, and decrease for further increase in the speed.

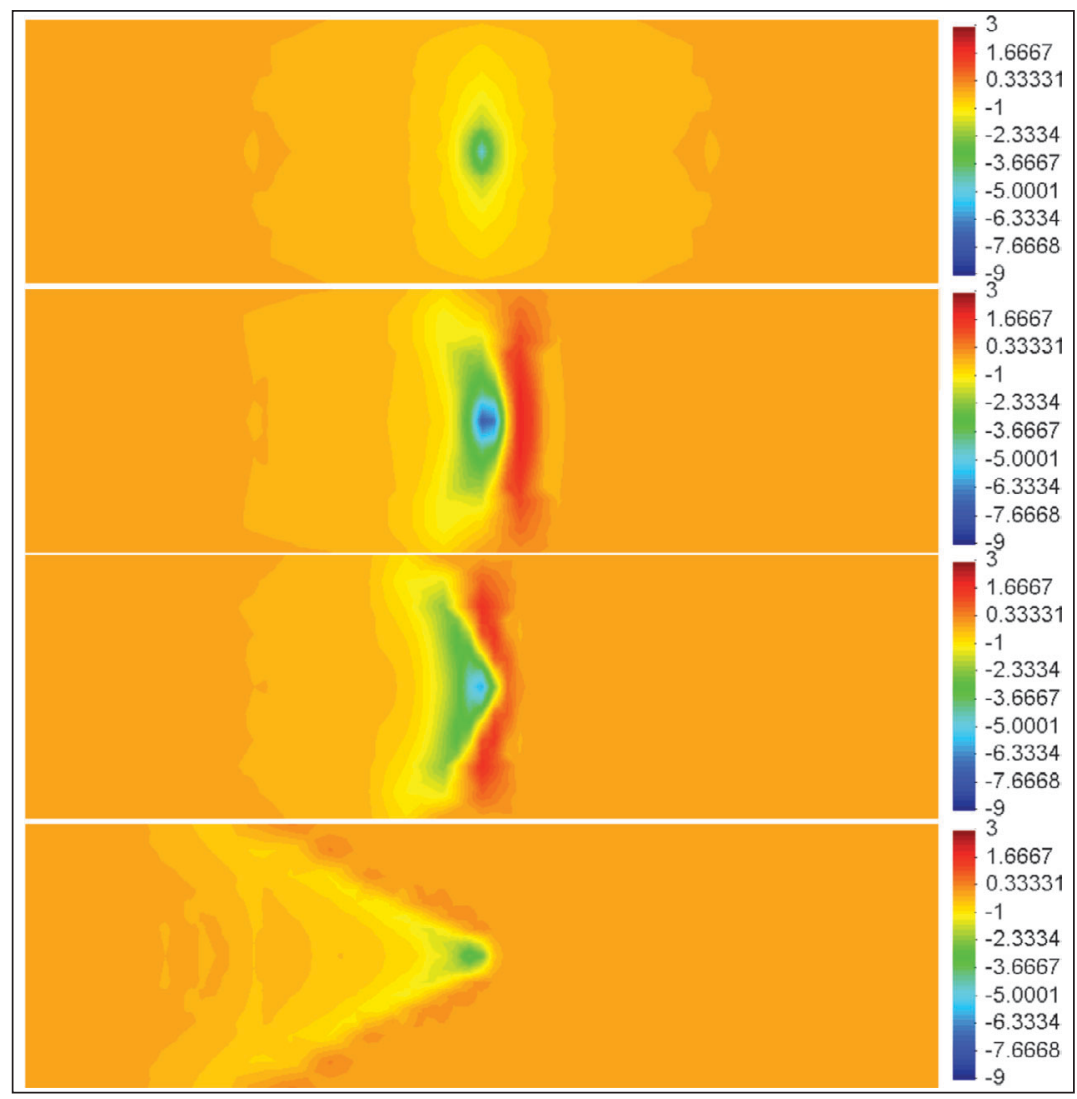

Figure 1. Vertical soil surface dimensionless displacements G( $\tau$ ): (a) $0<v<C_{R}$; (b) $C_{R}<v<C_{S}$; (c) $C_{S}<v<C_{P}$ and (d) $C_{P}<v<\infty$

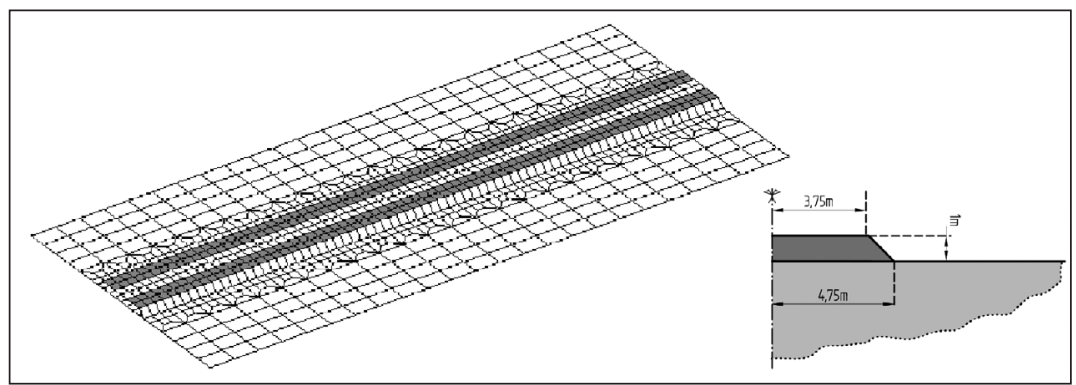

Figure 2. Half-space with $1.0 \mathrm{~m}$ thick ballast embankment. BE discretization and geometry.

\section{Homogeneous half-space motion due to train passage}

A problem of soil vibrations induced by a HST passage will be studied next. The train is considered to be a set of axle loads travelling at constant speed and the soil a uniform viscoelastic half space.
The load is assumed to be transmitted to the soil by each couple of wheels through the sleepers according to the load distribution proposed by Krylov [7]. The analysis of the soil vibrations induced by a high speed train on a homogeneous viscoelastic half-space with a ballast layer $1 \mathrm{~m}$ thick is carried out using the mesh of Figure 2 which has a total length of $86.4 \mathrm{~m}$, a width of $37 \mathrm{~m}$. The train is represented by an array of loads corresponding to the axles location and load values of trains Thalys Alstom [8].

In 1997, Degrande [8] made a set of experimental measurements for this train just before the inauguration of the high-speed train track between Brussels and Paris. Here, these valuable data will be used for comparison with numerical results obtained using the proposed technique.

Displacement records at any point on the boundary element mesh are obtained from the numerical analysis. Points on the crosssymmetry axis of the discretized zone are taken as a reference. Figure 3 corresponds to the time records of the vertical component velocity at a surface point located at $8 \mathrm{~m}$ from the track axis for train speed values $\mathrm{v}=315 \mathrm{~km} / \mathrm{h}, \mathrm{v}=300 \mathrm{~km} / \mathrm{h}, \mathrm{v}=271 \mathrm{~km} / \mathrm{h}$ and $\mathrm{v}=256 \mathrm{~km} / \mathrm{h}$. Experimental data and timedomain computed values are shown in the Figure 3.

Frequency spectra for the numerical results were obtained using the Fourier transform. Frequency spectra are shown in Figure 4 for a distance of $8 \mathrm{~m}$ to the track axis. It can be observed from this figure that numerical results are dominated by bogie and axle passage frequency (low frequency). This part of the numerical results spectra corresponds closely to the experimental results spectra. However, the intermediate frequency content of the experimental results spectra, corresponding to wheel and rail irregularities, are not shown by the time records and frequency spectra of the numerical results as they are not included in the load model.

In this analysis is observed that in all cases, the time length of the main perturbation, the normal peak particle velocity (PPV) values and the dominant frequency corresponding to bogies and axle passage are accurately represented in the numerical solution. There is good agreement between numerical results and experimental measures. The present approach can be employed to properly the time history of soil surface motion at a significant area around the track, including the attenuation effects, for different train speeds. 


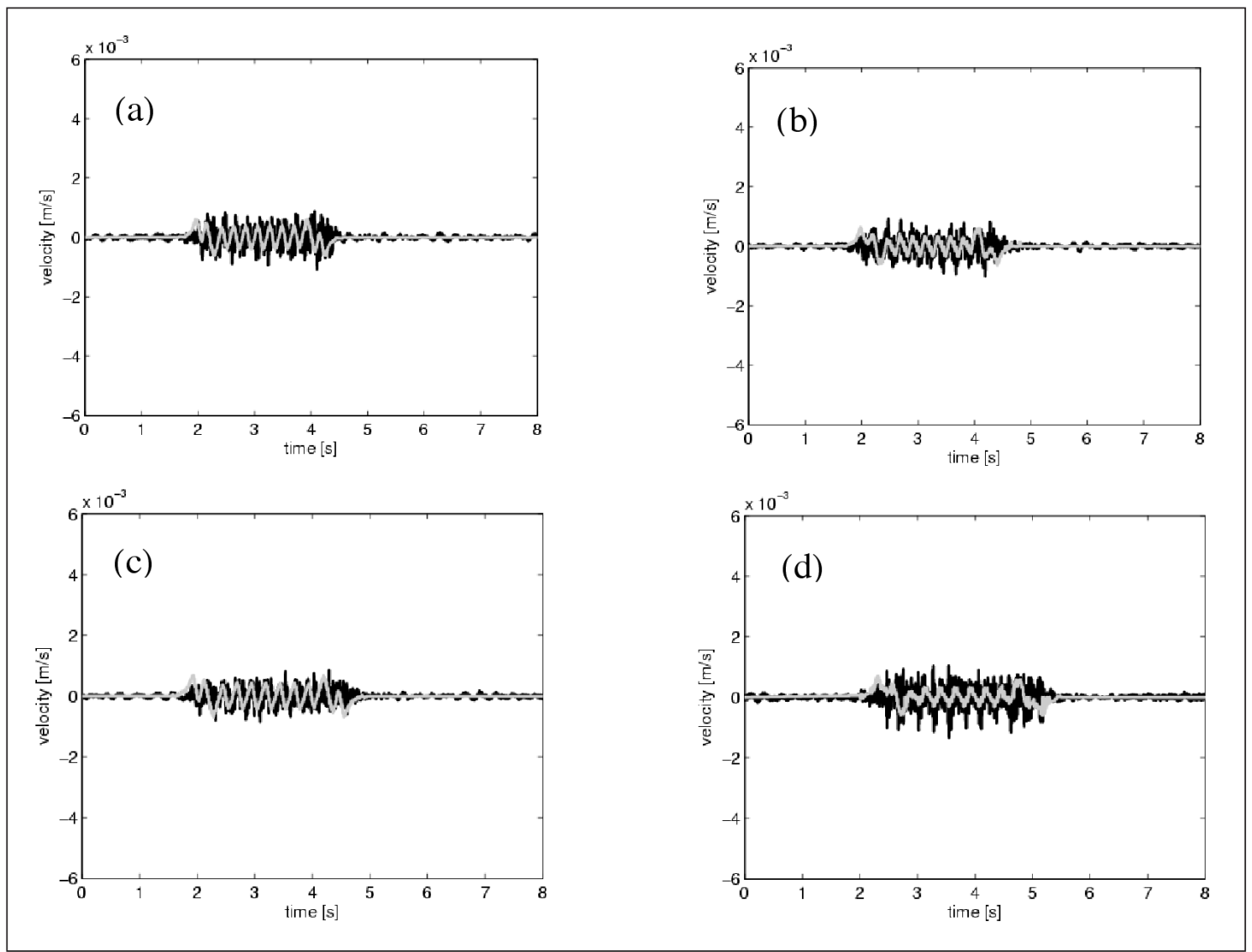

Figure 3. Vertical velocity at a point $8 \mathrm{~m}$ from the track: (a) $v=315 \mathrm{~km} / \mathrm{h} \mathrm{(b)} v=300 \mathrm{~km} / \mathrm{h}(\mathrm{c}) v=271 \mathrm{~km} / \mathrm{h}$ (d) $v=256 \mathrm{~km} / \mathrm{h}$. Experimental (black line) vs. Numerical (grey line)

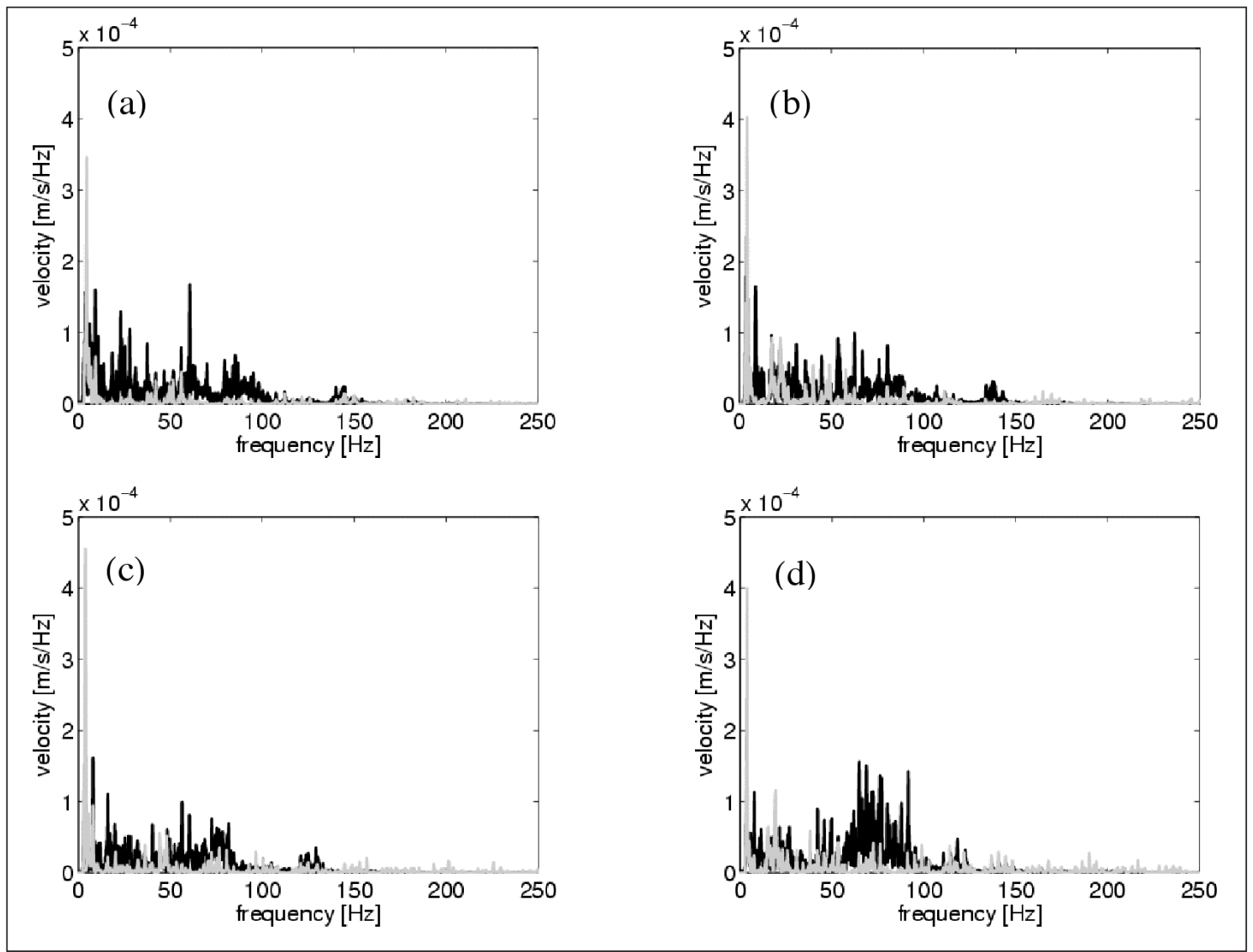

Figure 4. Frequency content of the vertical velocity at a point $8 \mathrm{~m}$ from the track: (a) $v=315 \mathrm{~km} / \mathrm{h}(\mathrm{b})$ $v=300 \mathrm{~km} / \mathrm{h}(\mathrm{c}) v=271 \mathrm{~km} / \mathrm{h}(\mathrm{d}) v=256 \mathrm{~km} / \mathrm{h}$. Experimental (black line) vs. Numerical (grey line) 


\section{Dynamic interaction with structures}

One of the important things to be analyzed in the project of high-speed train lines is the dynamic effects on surface and underground structures next to the track. The present numerical model allows for a realistic representation of these effects taking into account in a rigorous manner dynamic soilstructure interaction. Soil and structure are included in the same 3-D model and full interaction is considered. To show the capabilities of the approach two practical engineering problems will be studied. First, the dynamic response of a steel structure supporting the overhead contact line is studied and the computed results are compared with those obtained during the certification testing of the high-speed line between Córdoba and Málaga [6]. Second, the soil motion and the HST effects on a concrete underpass when a train passes at $300 \mathrm{~km} / \mathrm{h}$ speed are studied [5].

During the certification testing of the highspeed line between Córdoba and Málaga, in addition to recording vibrations induced in the soil, the dynamic response of a steel structure supporting the overhead contact line was also studied. This was accomplished by recording traffic vibrations transmitted to the structure as shown in Figure 5. The structure, situated at a distance of 3.350 from the centre of the track, is $9.86 \mathrm{~m}$ high with a $700-\mathrm{kg}$ electrical transformer mounted on it at a height of 5.0 m.. Figure 6 shows vibration velocity values produced by an AVE Alstom train travelling at a speed of $298 \mathrm{~km} / \mathrm{h}$.

In order to experimentally validate the numerical model, the dynamic response of the structure was computed. Figure 6 shows the response, obtained with the numerical model proposed herein, in the direction perpendicular to the track at a point $2 \mathrm{~m}$ from the structure's footing. As with the measured response, the passing of every axle can also be observed. The comparison of the numerically

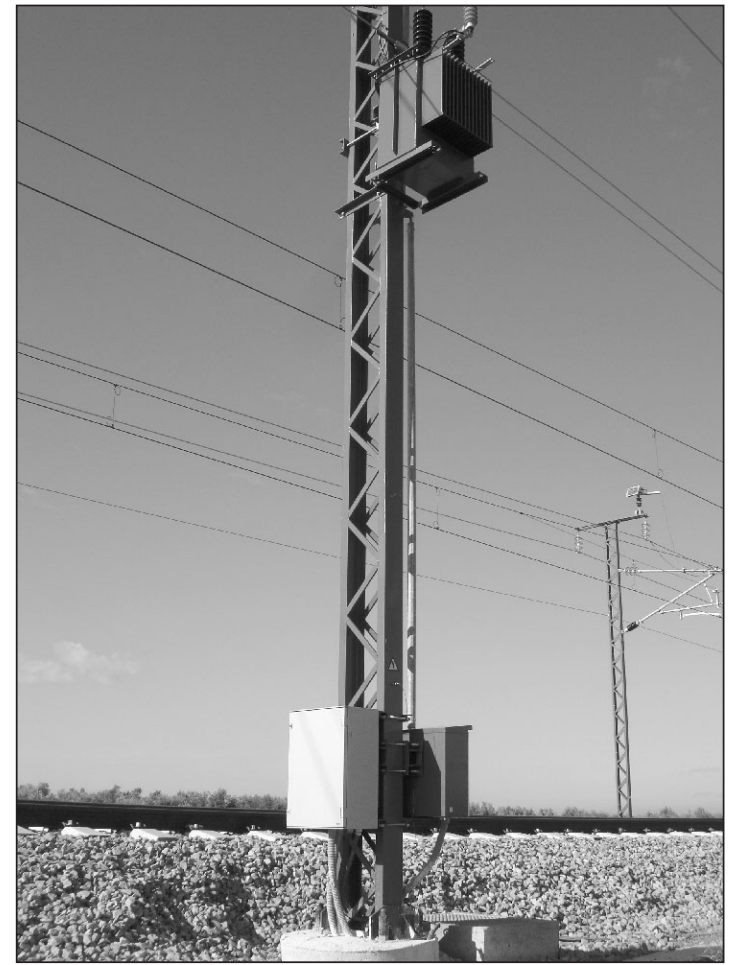

Figure 5. Overhead contact line support structure

and experimentally obtained time histories response highlights the reliability of the numerical model.

Now, the soil motion and the HST effects on a concrete underpass when the train passes at $300 \mathrm{~km} / \mathrm{h}$ speed are studied. The geometry of the problem and discretization for soil and structure are shown in Figure 7 . The train passes along an embankment on a uniform half-space. The underpass is a concrete plate type structure with the geometry shown in Figure 7.

Figure 8 shows vertical displacements at three half-space surface reference points for the train passage. The three points are shown in Figure 7 as A1, A2 and A3. Their distances to the track axis is $11.5 \mathrm{~m}$ and their distance to the plane of symmetry is $23.4 \mathrm{~m}, 3.6 \mathrm{~m}$ and $0 \mathrm{~m}$, respectively. The bogie passage effect can be seen at the three locations. The maximum
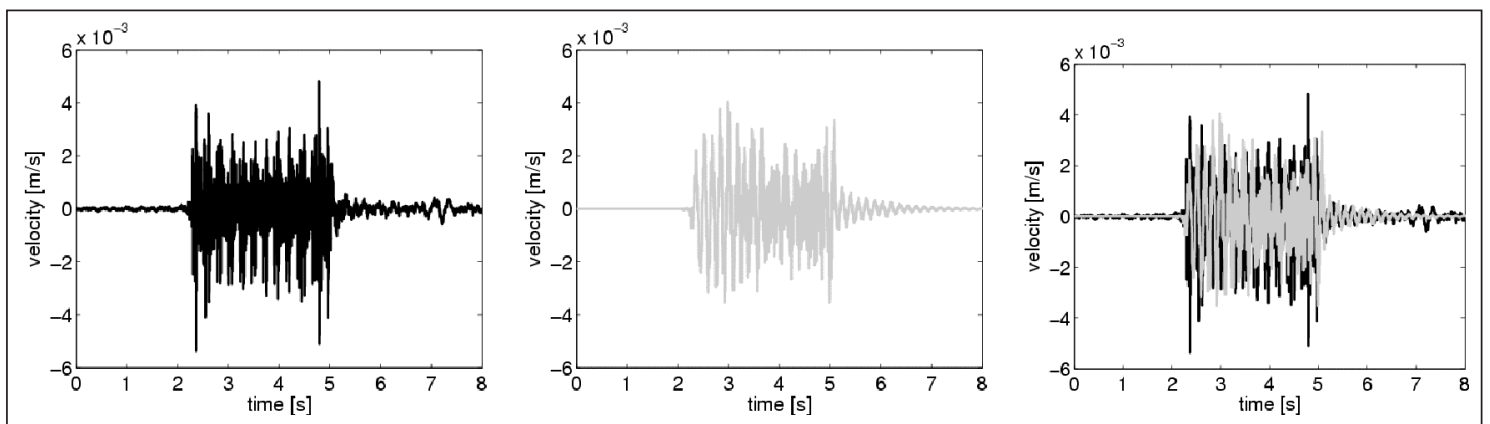

Figure 6. Time history of the vertical velocity in the support structure at the passing of an AVE-Alstom train travelling at a speed, $v=298 \mathrm{~km} / \mathrm{h}$ on Track 1. Experimental Result (black line) vs. Numerical Result (grey line) 


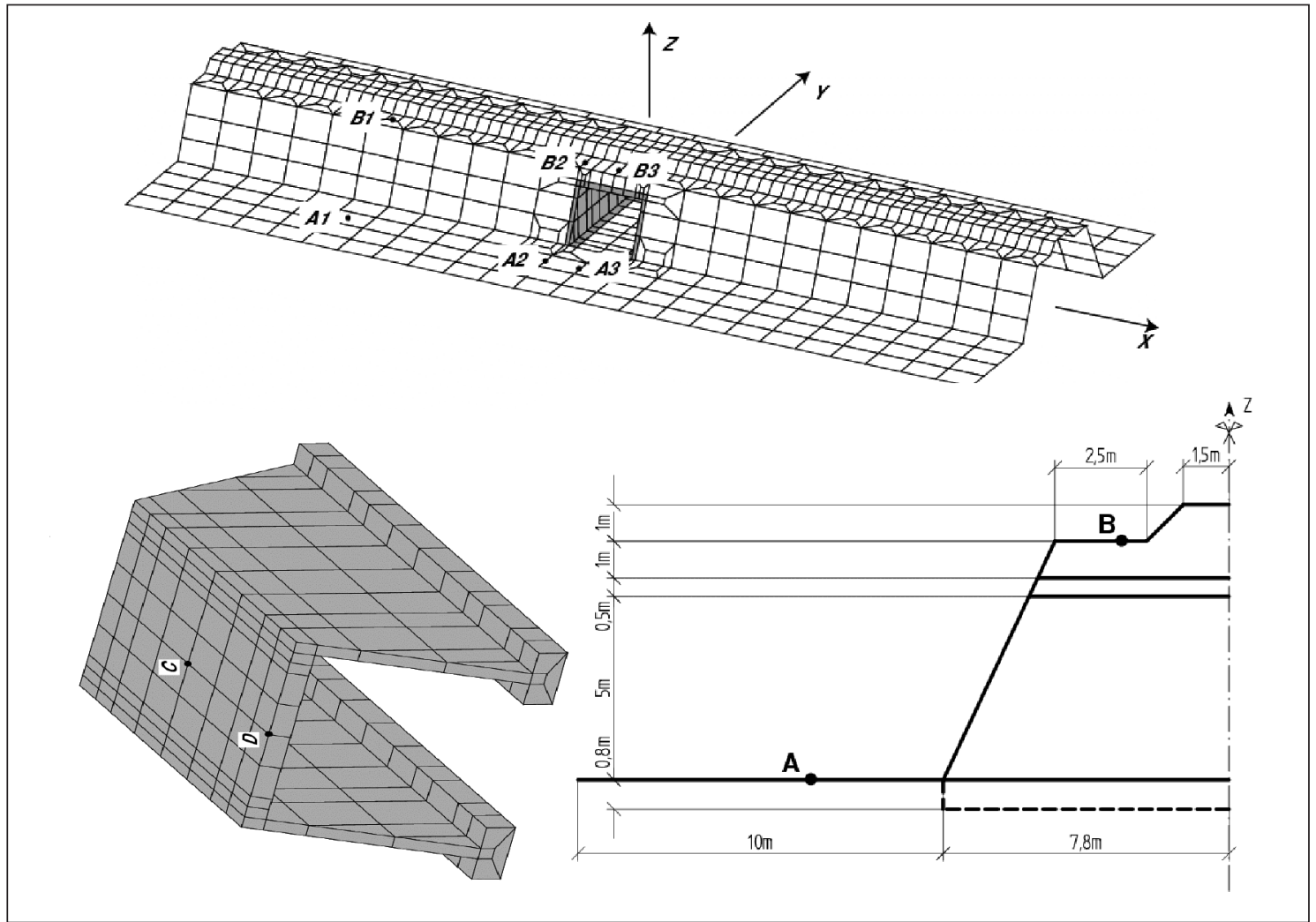

Figure 7. Underpass. BE discretization and geometry
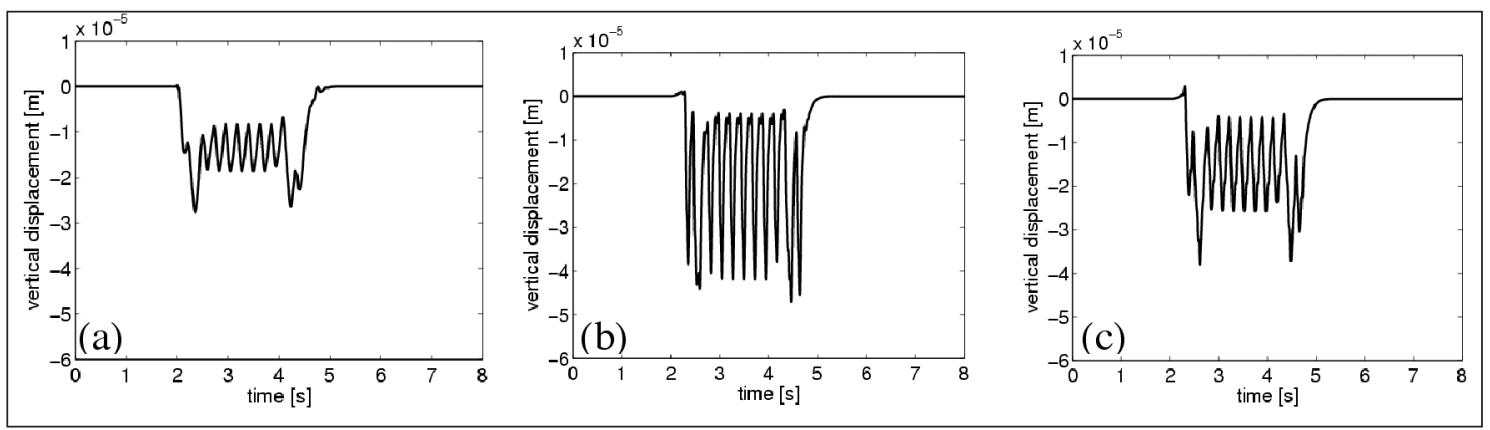

Figure 8. Vertical displacement at three points located $11.45 \mathrm{~m}$ from the track axis due to the passage of an Alstom HST with $v=300 \mathrm{~km} / \mathrm{h}$ : (a)Point A1 (b)Point A2 (c)Point A3.
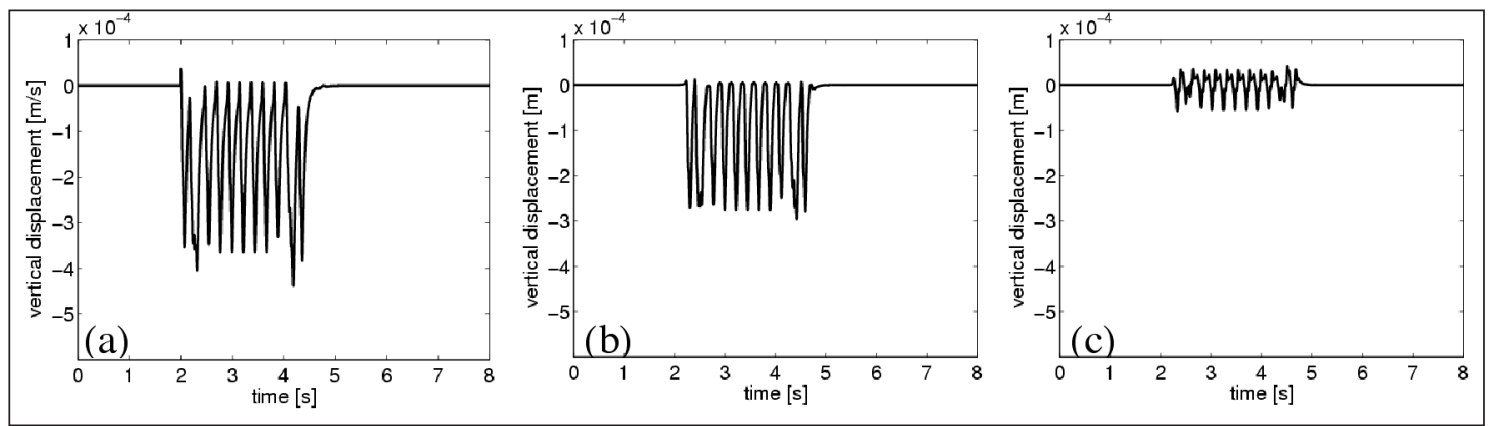

Figure 9. Vertical displacement at embankment surface points located $3.60 \mathrm{~m}$ from the track axis due to the passage of an Alstom HST with $v=300 \mathrm{~km} / \mathrm{h}$ : (a)Point B1 (b)Point B2 (c)Point B3.

displacements of the three points shown, take place at point A2 due to the load transmitted to the soil surface through the concrete walls, whereas point A3 at the plane of symmetry take intermediate values. In any case, displacements at the half-space surface are much smaller that those at embankment point closer to the track.

Vertical displacements at points B of the embankment at distance $\mathrm{Y}=3.5 \mathrm{~m}$ from the track axis are shown in Figure 9. Values for three points, B1, B2 and B3 are shown. The 

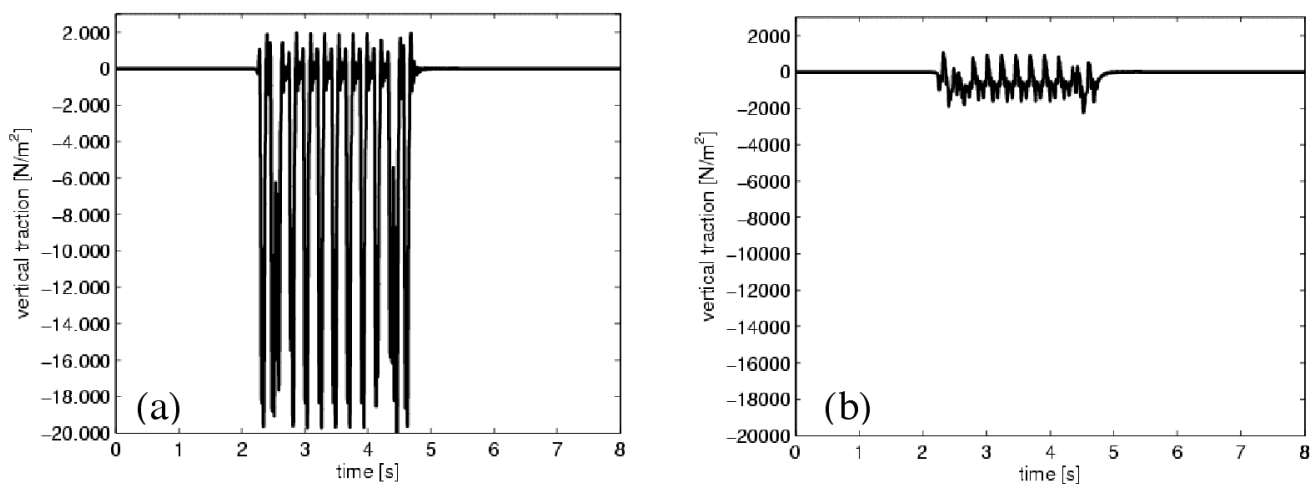

Figure 10. Tractions on the underpass deck due to the passage of an Alstom HST with $v=300 \mathrm{~km} / \mathrm{h}:(\mathrm{a})$ Point $C$ (b) Point $D$.

peak displacement values due to the train passage are of one order of magnitude larger than those for the soil surface and decrease very significantly when the point is over the under-pass structure due to its stiffening effect.

Traction values at the underpass deck due to the HST passage are also directly obtained from the model. The time history for two different points $\mathrm{C}$ and D of the deck cross track axis of symmetry are shown in Figure 10. Point $\mathrm{C}$ is the centre point of the deck and point $\mathrm{D}$ is on the deck external boundary. As expected, tractions take their maximum values under the sleepers zone and decrease towards the deck external boundary.

\section{Conclusions}

A numerical model has been applied to the analysis of soil motion due to high-speed train passage. The model is based on time domain $\mathrm{BE}$ and $\mathrm{FE}$ formulations. In contrast to most of the previously proposed models for predicting vibrations induced by rail traffic, a fully three dimensional methodology is used in this paper in order to be able to consider heterogeneous soil conditions, the presence of drainage systems, underpasses, tunnels or other structures in the proximity of the track. Furthermore, the model lends itself to real discretization of the problem, meaning that track geometry, ballast or slab effects and other miscellaneous local effects can be taken fully into account.

The numerical model was thoroughly validated by the experimental data recorded at the sleepers, different points on the soil surface and at one of the overhead contact line support structures during the certification testing of the Bruselas-Paris [8] and Córdoba-Málaga high-speed lines [6]. The measurements were acquired at the passing of different types of trains travelling at speeds ranging from 151 to $315 \mathrm{~km} / \mathrm{h}$.
The comparison of numerically predicted and experimentally recorded results demonstrate that the model formulated is reliable for analysing and predicting the amplitude of vibrations produced in the soil by the passing of HSTs. The model can be used to formulate design recommendations for structures to be located near the tracks, to identify the causes of high vibration levels and to evaluate measures that could be taken to attenuate them.

\section{References}

1. J. Domínguez. Boundary elements in dynamics. Southampton, Boston, London, New York: Computational Mechanics Publications and Elsevier Applied Science; 1993.

2. OC. Zienkiewicz. The finite element method. London: McGraw-Hill Company; 1977.

3. O. von Estorff, C. Hagen. Iterative coupling of FEM and BEM in 3D transient elastodynamics. Engineering Analysis with Boundary Elements 29 (2005) 775-87.

4. P. Galvín, J. Domínguez. Analysis of ground motion due to moving surface loads induced by high-speed trains. Engineering Analysis with Boundary Elements 31 (2007) 931-41.

5. P. Galvín, J. Domínguez. High speed train-induced ground motion and interaction with structures. Journal of Sound and Vibration 307 (2007) 755-77.

6. P. Galvín, J. Domínguez. Experimental and numerical analyses of vibrations 
induced by high-speed trains on the Córdoba-Málaga line. Soil Dynamics and Earthquake Engineering 2008; doi:10.1016/j.soildyn.2008.07.001.

7. V. Krylov, Effects of track properties on ground vibrations generated by highspeed trains, Acustica-Acta Acustica 84 (1998) 78-90.
8. G. Degrande, Free field vibrations during the passage of a high speed train: experimental results and numerical predictions, in: V. Krylov (Ed.), Noise and Vibration from High-speed Trains, Thomas Telford Publishing, London, 2001.

\section{Canadian municipalities discussing LFN bylaw}

Representatives from 12 Canadian municipalities have met to discuss whether or not they wanted to support a test bylaw that would regulate low frequency noise (LFN). And, after hearing Huron East solicitor Greg Stewart explain how such a bylaw would be created and its anticipated cost of close to $\$ 60,000$, municipalities from Norwich to Melancthon to Saugeen Shores returned to their councils in hopes of bringing an answer back to Huron East by the end of December. "We couldn't get the full councils here so this was an information session to see if they were interested. We'll be waiting to hear if they're willing to join the test case. I know some people will think we're not moving fast enough and it's not that we're scared - we just have to do it right," said Huron East Mayor Joe Seili after the meeting. Stewart told the municipalities, that Huron East is proposing a test bylaw to regulate low frequency noise after receiving concerns from community members about the health problems caused by industrial wind turbines. "Low frequency noise is a bit of an unknown with studies done mostly in Europe and council felt that the unexplained elements needed to be addressed. They decided to look at the possibility of a bylaw but to have it tested by a court before they put it into effect," said Stewart. Stewart explained that since the province's Green Energy Act has removed municipality's authority under planning legislation about the siting of wind turbines, they are left with the Municipal Act's section allowing municipalities to regulate public nuisances, including noise and vibrations to protect their residents' health, safety and wellbeing. "The words and opinion of council are important because if the bylaw is arrived at in good faith, it's not reviewable by a court," he said. Stewart warned that the bylaw cannot target wind turbines specifically but would need to include any industrial "noise emitter" in the municipality. "We can't thwart the actions of a particular group or the court will strike it down. It has to be across the board," he said.

\section{Is a local anti-noisy vehicle law practicable?}

About 30 per cent of the 2,000 noise complaints received by Calgary Council each year are about loud vehicles. City council sidelined in July a proposal to toughen the bylaws and target excessive noise caused by vehicles. Instead, council opted for more study on the issue before setting out new rules or souped-up penalties and asked for a report outlining the definition of excessive vehicle noise and the appropriate penalties; available noise enforcement options including the use of technology; and a cost estimate for the technology and any constraints in provincial and federal legislation. Ald. John Mar had spearheaded the initiative supported by eight other aldermen which seeks to put a maximum decibel level into the bylaw. He said most Calgarians have no idea how loud their vehicles are on the road. Mar added the loudest vehicles or motorcycles legally imported or made in Canada run about 90 decibels. To give some leeway, 96 decibels was decided as a reasonable limit. "No imported or manufactured vehicle in this country goes over that output unless you go out and intentionally modify your vehicle," said March. Rob Leech, owner of Calgary's Tunerworks Performance questioned how authorities would enforce a 96-decibel limit. "How are they measuring the decibels? Is it with the car on standby or are you revving the motor, or is the car in motion?" asked Leech, who said he'd most likely go to an open house. Leech noted the decibel system is a knee-jerk reaction from those who don't understand the automotive industry. He said there would have to be a national policy on vehicles for Calgary to police decibels - otherwise people would be forced to park their cars on the outskirts of the city. 